\title{
Movimento Feminista e Reconhecimento das Donas de Casa na Obra de Clarice Lispector
}

\begin{abstract}
Mariana Paiva Frizzera
Mestre em Direitos e Garantias Fundamentais (2018) e Especialização em Direito Processual Civil (2016) pela Faculdade de Direito de Vitória (FDV). Graduada em Direito pela Faculdade de Direito de Vitória (2014). Tem experiência na área de Direito, com ênfase em Direito Privado. Pesquisadora na área de Direito do Consumidor, Direitos Humanos, questões relacionadas às mulheres, gênero e igualdade. http://buscatextual.cnpq.br/buscatextual/visualizacv.do?id=K8784772P6. https://orcid.org/0000-0001-6019-0879. mari_frizzera@hotmail.com
\end{abstract}

\section{Nelson Camatta Moreira}

Pós-doutor em Direito pela Universidad de Sevilla (bolsa Capes). Pós-doutor em Direito pela Universidade do Vale do Rio dos Sinos (Unisinos). Doutor em Direito pela Unisinos, com estágio anual na Universidade de Coimbra (bolsa Capes). Mestre em Direito pela Unisinos (bolsa Capes). Professor do Programa de Pós-Graduação Stricto Sensu (Doutorado e Mestrado) e da Graduação em Direito da Faculdade de Direito de Vitória (FDV-ES). Líder do Grupo de Pesquisa CNPq Teoria Crítica do Constitucionalismo, da FDV. Líder do Grupo de Estudos Direito e Psicanálise (FDV-ES/Escola Lacaniana de Psicanálise de Vitória). Profesor Invitado, adjunto al Programa Academic Visitor de la Facultad de Derecho de la Universidad de Sevilla. Miembro del Grupo de Investigación Antagónicos de la Facultad de Derecho de la Universidad de Sevilla. Colaborador en Seminarios con la Cátedra Abierta de Derecho y Literatura de la Universidad de Málaga. Presidente (biênio 2019-2020) e membro honorário da Rede Brasileira Direito e Literatura (RDL). Coordenador do Projeto de Extensão Café, Direito e Literatura (FDV-ES). Tem experiência em gestão de curso acadêmico e no Direito, com ênfase em Direito Público, especialmente nos seguintes temas: Direito Constitucional, Direitos Fundamentais, Hermenêutica, Filosofia do Direito, Direito e Literatura e Direito e Psicanálise. http://buscatextual.cnpq.br/buscatextual/visualizacv.do?id=K4772095Z3. https:// orcid.org/0000-0002-8295-4275. nelsoncmoreira@hotmail.com

Este artigo aborda a ausência de reconhecimento das mulheres que realizam trabalho doméstico não remunerado, seja em tempo integral, seja na dupla jornada. Para tanto, toma-se como base o conto "A imitação da rosa", presente no livro Laços de Família, de Clarice Lispector, com o objetivo de expor o conflito enfrentado por diversas mulheres referente ao não reconhecimento do espaço privado e do trabalho doméstico, situação ainda vivenciada no século 21. Analisa-se a teoria do reconhecimento desenvolvida por Axel Honneth e Nancy Fraser, expressando as suas contradições e buscando compatibilizá-las de modo a permitir a ressignificação dessas mulheres. Por fim, será abordada a importância do autorreconhecimento das mulheres na articulação de um movimento feminista que busque atingir essa finalidade, permitindo a sua participação na condição de pares na esfera social.

Palavras-chave: Trabalho doméstico. Reconhecimento. Movimento feminista.

FEMINIST MOVEMENT AND RECOGNITION OF HOUSEWIVES IN THE LITERARY WORK OF CLARICE LISPECTOR

ABSTRACT

This article brings up the absence of recognition of the women who do unpaid domestic work, full time, or in double shift. Therefore, it is taken as a basis the tale "A imitação da rosa", which is present in the book "Laços de Família", by Clarice Lispector, with the objective of showing the conflict faced by several women for not having the recognition of private space and domestic work, a situation still lived in the 21 century. It is analysed the theory of recognition developed by Axel Honneth and Nancy Fraser, expressing their contradictions and trying to make them compatible, in a way that permits the resignification of these women. Finally, it will be raised the importance of their self-recognition in the articulation of a feminist movement that searches to reach this purpose, allowing their participation as peers in the social sphere.

Keywords: Domestic work. Recognition. Feminist movement.

SUMÁRIO

1 Introdução. 2 "Chatinha”, "Boa” e "Diligente": As Mulheres dos Anos Dourados. 3 A Teoria do Reconhecimento de Axel Honneth e Nancy Fraser. 4 A Metáfora da Rosa e a Importância dos Movimentos Feministas. 5 Considerações Finais. 6 Referências.

Recebido em: 2/5/2019

Aceito em: 4/11/2019 


\title{
INTRODUÇÃO
}

A proposta do presente trabalho é compreender a importância da atuação do movimento feminista no reconhecimento das mulheres que realizam trabalho doméstico não remunerado, seja de forma exclusiva, seja das que possuem dupla jornada. Para tanto, toma-se como base o conto "A imitação da rosa", presente no livro Laços de Família, de Clarice Lispector, a fim de expor como a igualdade presente na Constituição Federal é mascarada e como é perpetuada a relação de submissão da mulher a partir de um discurso masculino.

O movimento feminista foi essencial para o reconhecimento de inúmeros direitos às mulheres, como os direitos civis e políticos, o direito ao controle de reprodução, o direito à educação superior, o direito não só ao trabalho, mas a ocupar altos cargos em profissões consideradas masculinas, entre outros. Nota-se, contudo, que o foco do feminismo, atualmente, está voltado apenas às mulheres educadas de classe média, encorajando-as a romper barreiras e a alcançar altos cargos corporativos. Por conseguinte, apenas as mulheres profissionais são beneficiadas.

Em razão disso, é importante o estudo do tema a partir da teoria do reconhecimento de Axel Honneth e Nancy Fraser, como forma de ressignificar a mulher que realiza atividades não remuneradas.

Será estabelecida uma conexão entre a Literatura e o Direito para compreender a representação da mulher doméstica que é delineada por Clarice Lispector em "A imitação da rosa", conto que traduz o conflito provocado pelo não reconhecimento, elemento central do presente estudo. A interpretação de textos literários tem como objetivo revelar as injustiças sociais a que estão submetidos as pessoas e os grupos, tradicionalmente excluídos, que tiveram o seu poder de fala silenciado.

\begin{abstract}
Acabei de focalizar a relação da literatura com os direitos humanos de dois ângulos diferentes. Primeiro, verifiquei que a literatura corresponde a uma necessidade universal que deve ser satisfeita sob pena de mutilar a personalidade, porque pelo fato de dar forma aos sentimentos e à visão do mundo ela nos organiza, nos liberta do caos e, portanto, nos humaniza. Negar a fruição da literatura é mutilar a nossa humanidade. Em segundo lugar, a literatura pode ser um instrumento consciente de desmascaramento, pelo fato de focalizar as situações de restrições dos direitos, ou de negação deles, como a miséria, a servidão, a mutilação espiritual. Tanto num nível quanto no outro ela tem muito a ver com a luta pelos direitos humanos (CANDIDO, 2011 , p. 188).
\end{abstract}

Nesse sentido, o conto "A imitação da rosa" critica o modelo familiar tradicional imposto pela sociedade patriarcal, o qual é responsável pelo conflito enfrentado por diversas muIheres referente ao não reconhecimento do espaço privado e do trabalho doméstico, situação ainda vivenciada no século 21 .

O livro Laços de Família foi publicado em 1960, tempo conhecido como Anos Dourados, o qual correspondeu aos anos de 1945 a 1964. Nesse contexto, o Brasil presenciou a ascensão da classe média entre 1950 e 1954, época marcada pela eleição direta e o suicídio de Getúlio Vargas. Em decorrência do fim da Segunda Guerra Mundial, e do consequente otimismo, imperava no Brasil o crescimento urbano e a industrialização. 
Posteriormente, o governo de Juscelino Kubitschek proporcionou um estilo de vida baseado nas tecnologias, na produção em massa e, desse modo, os eletrodomésticos começaram a chegar ao Brasil, tais como liquidificadores, televisores, entre outros, importando o American Way of Life. Em relação à cultura, há o surgimento da bossa nova e a arquitetura de Lúcio Costa e Oscar Niemeyer expande-se pelo mundo. Juscelino Kubitschek governou o Brasil por meio de um discurso progressista, marcado pela organização das cidades e pela contínua ascensão da classe média, camada social que possui características e anseios próprios. A obra de Clarice Lispector é centrada nessa nova estrutura social.

Laços de Família é formado por um conjunto de contos que têm em comum o fato de retratarem os elos familiares que unem homens e mulheres da camada pequeno-burguesa da sociedade, concedendo especial atenção à figura da mãe-mulher inserida no seu cotidiano. Segundo Lucia Helena (1997, p. 27), Clarice Lispector vale-se da figura feminina "[...] como mote insistente para investigar não só a singular emergência da mulher na sociedade, marcada por enorme repressão, mas principalmente para recolocar a questão da mulher e da inscrição do sujeito na história".

Há anos as mulheres brasileiras trabalham, tendo participado do processo de elaboração da Constituição de 1988, quando diversos direitos referentes à vida e ao trabalho foram definidos e melhorados. Principalmente a partir dos anos 80 elas se afirmaram no mercado de trabalho, entretanto ainda são patentes as desigualdades entre os sexos, sejam elas de natureza econômica, política ou de acesso aos postos de poder. No âmbito doméstico não há divisão do trabalho, havendo uma dedicação muito maior das mulheres.

Nesse sentido, cresce entre as mulheres brasileiras a luta pela diferença, pela valorização da sensibilidade e dos valores femininos, querendo ser mães, trabalhadoras, cidadãs e sujeitos de seu lazer e prazer, concomitantemente. A esfera do trabalho doméstico, entretanto, ainda permanece sem reconhecimento e, por esse motivo, justifica-se a pertinência deste estudo impulsionado pela seguinte indagação: Como o movimento feminista conseguirá assegurar os direitos e o respeito das mulheres que realizam trabalho doméstico não remunerado e das que desenvolvem dupla jornada?

Com o objetivo de responder esse questionamento, parte-se da hipótese de que os importantes e históricos movimentos feministas devem ser revisitados e atualizados a fim de englobar outras classes de pessoas e de atingir novas questões. Para tanto, a temática do movimento feminista será incorporada à teoria do reconhecimento inspirada nas matrizes teóricas de Axel Honneth e Nancy Fraser.

Para enfrentar esse problema o presente trabalho baseia-se no método dialético, em decorrência da contradição existente entre os direitos conquistados pelas mulheres nas últimas décadas e a ausência do reconhecimento do trabalho não remunerado realizado por elas.

Dessa forma, o artigo foi dividido em três partes. A primeira abordará o padrão ideal de mulher presente nos Anos Dourados, tendo como núcleo orientador o conto "A imitação da rosa", de Clarice Lispector. A segunda analisará a teoria do reconhecimento desenvolvida por Axel Honneth e Nancy Fraser. A terceira discutirá a possibilidade de compatibilizar as duas teorias críticas, aplicando-as no caso das mulheres que realizam trabalho doméstico e ainda abordará a importância do movimento feminista para alcançar o seu reconhecimento. 


\section{2 "CHATINHA", "BOA" E "DILIGENTE": AS MULHERES DOS ANOS DOURADOS}

A narrativa de "A imitação da rosa" tem como protagonista Laura, esposa de Armando, que vive no espaço privado da casa e do cotidiano da vida doméstica. Os fatos passam-se na mente da personagem principal e são divididos em três tempos, quais sejam: passado, presente e futuro. O passado remonta ao tempo da obediência, da subordinação e ao tempo da ruptura, em que ela é internada. O presente representa o momento em que ela volta para casa e relembra os dois passados. Já o futuro é quando ela tenta resgatar o passado da submissão (COQUEIRO; SEGATO, 2012, p. 4).

A fim de entender o conflito vivenciado por Laura é necessário primeiro analisar o contexto histórico em que ela estava inserida. Conforme referido anteriormente, nas décadas de 50 e 60 do século 20 o Brasil passou por uma época de grande industrialização e isso possibilitou a educação e a profissionalização das mulheres. Não houve, todavia, uma modificação da mentalidade da sociedade, que continuava distinguindo os papéis femininos dos masculinos e o trabalho da mulher ainda era cercado de preconceitos e considerado subsidiário ao trabaIho do homem (DEL PRIORE, 2013, p. 71). A família conjugal é o modelo dominante, composta por pai, mãe e filhos, embora estes sejam em menor número em comparação ao passado. Os padrões de casamento são mantidos, com a autoridade máxima sendo conferida ao pai, considerado o "chefe da casa" (PINSKY, 2014, p. 18).

Trata-se, então, de uma sociedade contraditória, visto que, de um lado, os brasileiros têm mais acesso às informações sobre a emancipação feminina em outros países, decorrente da maior possibilidade de participação das mulheres no mercado de trabalho e da chegada da pílula anticoncepcional no início dos anos 60. Por outro lado, há um incentivo, realizado por campanhas governamentais, "[...] aos valores tradicionais da família, às virtudes da maternidade e à dedicação exclusiva da mulher ao lar para que os homens reassumam seus postos de trabalho abandonados com o advento da guerra [...]" (PINSKY, 2014, p. 19).

Esse conflito é refletido em Laura, a qual teve de ser internada, em decorrência das suas inquietações referentes às convenções exigidas pela sociedade patriarcal, uma vez que, como mulher, é a responsável pela felicidade conjugal e pela harmonia do casal. A sua saúde e o seu equilíbrio não eram levados em consideração, pois o que importava era agradar ao homem.

Nessa época, era comum as donas de casa de classe média viverem a "experiência do isolamento" em razão de passarem muito tempo em casa. Frequentemente elas eram acometidas por indisposições, ansiedade e insatisfações, pois eram educadas para adquirir um senso detalhista e quase obsessivo por limpeza, eram condicionadas a manter as aparências e a viverem em torno das tarefas domésticas e das necessidades dos familiares. É provável que uma parcela das dores e agonias vivenciadas pelas mulheres decorria do conflito entre as determinações de seus papéis e a realidade de sua vida. Ademais, as revistas recomendavam que as mulheres não discutissem ou reclamassem e que colocassem os seus desejos em segundo plano, sendo instruídas a não contestarem as desigualdades da dupla moral sexual, fato que podia acionar as válvulas de escape físicas e emocionais (PINSKY, 2014, p. 239). 
As revistas femininas culpavam as mulheres pelo "nervosismo feminino", pois elas se consideravam o "centro do mundo"; criticavam-nas, ao invés de abordarem as causas que levavam à insatisfação e ao descontentamento (PINSKY, 2014, p. 239-240). Desse modo, "não importavam os desejos ou a vontade de agir espontaneamente; o que contavam eram as aparências e as regras [...]" (DEL PRIORE, 2013, p. 67).

Ao voltar para casa, Laura deveria estar de novo "bem", contudo as aspas utilizadas no texto refletem o estado psicológico da personagem, que continuava descontente e insatisfeita, apesar de precisar manter uma postura "normal" diante da sociedade. A boa esposa e a mulher ideal era aquela que não reclamava, não criticava, não desafiava o marido, se vestia de forma sóbria, sem chamar a atenção.

Nota-se que a personagem não possuía uma identidade própria, visto que ela se submetia a uma vida metódica, representando o papel de uma esposa modelo, submissa e obediente (COQUEIRO; SEGATO, 2012, p. 5).

Com seu gosto minucioso pelo método - o mesmo que a fazia quando aluna copiar com letra perfeita os pontos da aula sem compreendê-los - com seu gosto pelo método, agora reassumido, planejava arrumar a casa antes que a empregada saísse de folga para que, uma vez Maria na rua, ela não precisasse fazer mais nada, senão 1의) calmamente vestir-se; 2ㅇ) esperar Armando já pronta; $3^{\circ}$ ) o terceiro o que era? Pois é. Era isso mesmo o que faria. E poria o vestido marrom com gola de renda creme (LISPECTOR, 1998, p. 35).

Ela, entretanto, não era uma mulher perfeita, pois não tivera filhos: "por acaso alguém veria, naquela mínima ponta de surpresa que havia no fundo de seus olhos, alguém veria nesse mínimo ponto ofendido a falta de filhos que ela nunca tivera?" (LISPECTOR, 1998, p. 35).

O presidente Vargas, em 1941, assinou um decreto estabelecendo que a educação feminina seria voltada para formar mulheres "afeiçoadas ao casamento, desejosas da maternidade, competentes para a criação dos filhos e capazes na administração da casa" (DEL PRIORE, 2013 , p. 66, grifos da autora). Desse modo, a mulher que não tinha filhos era julgada pela sociedade, pois para representar o modelo de mulher dos Anos Dourados ela precisava ser avaliada por sua condição de procriadora.

Laura, enquanto arruma a penteadeira, pensa como será o jantar com os seus amigos, Carlota e João, quando o seu marido conversaria com este sobre as coisas que saíam nos jornais, e ela falaria com Carlota sobre "coisas de mulheres", explicitando os papéis sociais destinados aos homens e às mulheres: "Armando esquecido da própria mulher. E ela mesma, enfim, voltando à insignificância com reconhecimento" (LISPECTOR, 1998, p. 34).

Nessa ocasião Laura também se questiona sobre há quanto tempo não havia Armando esquecido dela e há quanto tempo ela havia se esquecido de si mesma. Isso porque "[...] para pertencer ao padrão social vigente, é como se fosse necessário deixar de existir, matar a liberdade de ser, resultando em uma desestruturação existencial da identidade da personagem, representada, aqui, pelo 'olhar-se no espelho'”' (COQUEIRO; SEGATO, 2012, p. 6). 
Posteriormente, sentada no sofá da sala, Laura retoma o seu gosto pelo método, descrevendo o quanto gostava de passar as roupas de Armando e o cansaço advindo dessa tarefa, considerado uma recompensa. A ambição de sua vida era casar-se com um homem e agora que ela estava de volta não mais iria vivenciar a "terrível independência" (LISPECTOR, 1998, p. 38).

Nessa época estava vigente o Código Civil de 1916, o qual estabelecia que a mulher casada era relativamente incapaz, isto é, ela não podia decidir sobre o patrimônio e a prole. Todo o poder estava presente nas mãos do homem, considerado o chefe da família. Em 1962 há o reconhecimento da mulher como "companheira consorte" pelo Estatuto da Mulher Casada, possibilitando que ela colaborasse no orçamento familiar, mas, ao mesmo tempo, consolidava a ideia do homem como chefe da sociedade conjugal.

Ainda no sofá à espera de Armando, Laura adormece e quando abre os olhos ela nota um jarro de flores em cima da mesa. A beleza das rosas a incomodava: "Incomodava? Era um risco. Oh, não, por que risco? Apenas incomodava, eram uma advertência, oh não, por que advertência?" (LISPECTOR, 1998, p. 43-44). Esse momento em que Laura observa as rosas é denominado de epifania, o qual foi credenciado por James Joyce e representa o momento de revelação dos personagens e o reconhecimento de que algo importante está acontecendo em sua vida (BARBOSA, 2001, p. 123).

As rosas representam uma metáfora, fazendo com que Laura relembrasse o passado, tentando, novamente, romper com os ideais da sociedade patriarcal. Ela, da mesma forma que a maioria das mulheres da época, seguia os valores e as normas impostos pela sociedade, de modo que acabava desvalorizando-se como mulher.

Laura culpava-se por ter comprado as rosas e, por isso, pede à sua empregada, Maria, que as entregasse na casa de Carlota e João, todavia depois ela entra em um conflito interior, pois, na verdade, não queria se desfazer das rosas. Procura encontrar desculpas para impedir que a empregada leve as flores, como se devesse justificar cada uma das suas ações para todos ao seu redor. No final, ela entrega as flores para Maria, pois "[...] uma coisa bonita era para se dar ou para se receber, não apenas para se ter. E, sobretudo, nunca para se 'ser'" (LISPECTOR, 1998, p. 47).

Quando as rosas se vão, elas deixam um lugar claro dentro de Laura e ela tenta imitar as rosas dentro de si mesma, o que não era difícil. A personagem não percebe o tempo passar e quando Armando chega nota que Laura não é mais a sua esposa "chatinha", "boa" e "diligente": "Ela estava sentada com o seu vestidinho de casa. Ele sabia que ela fizera o possível para não se tornar luminosa e inalcançável" (LISPECTOR, 1998, p. 53).

Nas suas obras Clarice Lispector não só enfatiza a divisão existente entre homens e muIheres, como também ameaça o universo masculino por meio do momento epifânico, em que a mulher busca suplantar a sua posição submissa, transformando a tradicional relação masculino versus feminino (COQUEIRO; SEGATO, 2012, p. 9).

Essa falta de reconhecimento da esfera privada ainda está presente no século 21 e decorre da separação implícita ou explícita entre esta e a esfera pública. Elas passam a ser vistas como pontos eminentemente diferentes e, portanto, a vida privada é ignorada, uma vez que 
apenas a pública é merecedora de reconhecimento. Conforme veremos, essa diferenciação decorre da naturalização dos papéis sexuais desempenhados por homens e mulheres que permitiram também uma divisão entre os sexos no trabalho.

Posto isso, faz-se necessário analisar a teoria do reconhecimento desenvolvida por Axel Honneth e Nancy Fraser para, posteriormente, verificar a importância dos movimentos feministas na concretização de uma identidade para as mulheres que realizam tarefas domésticas, visto que até hoje estas não são consideradas, por muitos, um trabalho.

\section{A TEORIA DO RECONHECIMENTO DE AXEL HONNETH E NANCY FRASER}

A luta por reconhecimento social está ligada à ideia de constituição das sociedades modernas, ocasião em que os grupos considerados invisíveis na organização sociopolítica começaram a pleitear os seus direitos. Esse tema vem ganhando cada vez mais importância, surgindo como a forma de se desenvolver uma teoria crítica que possibilite interpretações, diagnósticos e novas formulações para os problemas das sociedades contemporâneas (MATTOS, 2006, p. 15).

No presente trabalho optou-se por utilizar as matrizes do reconhecimento de Axel Honneth e Nancy Fraser, expondo as principais ideias de cada um dos autores, de modo a estabelecer um diálogo entre eles.

A teoria desenvolvida por Honneth tem como objetivo demonstrar que todos os conflitos sociais têm como base uma luta por reconhecimento. Para tanto, ele vai buscar os primeiros trabalhos de Hegel, conhecidos como trabalhos da juventude de Jena, pois acredita que eles contêm alguns insights relevantes que não foram aprimorados pelo próprio Hegel (MOREIRA, 2010, p. 53-54).

Como Hegel desenvolveu uma teoria do reconhecimento de forma abstrata e metafísica e Honneth se propõe a comprovar de forma empírica o processo pelo qual ela passa, ele recorreu às pesquisas de Herbert Mead sobre Psicologia Social presente no processo de reconhecimento recíproco. Tanto Hegel quanto Mead entendem que a identidade depende do reconhecimento intersubjetivo e que a evolução da sociedade ocorre por meio das lutas por reconhecimento (MATTOS, 2006, p. 87-88).

Segundo a análise de Honneth (2007, p. 83), o centro da teoria do reconhecimento de Hegel está na ideia de que o progresso ético ocorre por meio de várias etapas, cada qual com padrões de reconhecimento cada vez mais exigentes, que são mediados por lutas intersubjetivas, nas quais os indivíduos tentam ganhar aceitação para reivindicações a respeito de sua própria identidade.

De acordo com a teoria de Mead, analisada por Honneth, um sujeito somente tem a possibilidade de adquirir uma autoconsciência quando "ele aprende a perceber sua própria ação na perspectiva, simbolicamente representada, de uma segunda pessoa". Isso ocorre porque um indivíduo não possui condições de intervir sobre si mesmo, de modo a compreender suas reações como produções da própria pessoa, sem a experiência de um parceiro que interagisse e reagisse com ele (HONNETH, 2003, p. 131). 
Em razão disso, Honneth (2003, p. 155) explica que a sua teoria "pode se tornar o fio condutor de uma teoria social de teor normativo; seu propósito é esclarecer os processos de mudança social reportando-se as pretensões normativas estruturalmente inscritas na relação de reconhecimento recíproco".

O estudo das relações intersubjetivas é voltado para o reconhecimento individual e recíproco dos indivíduos que fazem parte do meio social, contudo as estruturas de poder geram conflitos e tensões que podem dar origem aos movimentos de luta social, permitindo formas cada vez mais amplas de reconhecimento recíproco (HONNETH, 2003, p. 156). Interessante consignar que a luta social tem como base três esferas do reconhecimento recíproco: o amor, o direito e a solidariedade que representam, respectivamente, a necessidade de afirmação moral da autoconfiança, do autorrespeito e da autoestima.

O primeiro estágio do reconhecimento recíproco é o amor, o qual permite o desenvolvimento da autoconfiança nas relações. Novamente Honneth (2003, p. 160) recorre aos estudos realizados por Hegel, para quem o amor representa

[...] a primeira etapa do reconhecimento recíproco, porque em sua efetivação os sujeitos se confirmam mutuamente na natureza concreta de suas carências, reconhecendo-se assim como seres carentes: na experiência recíproca da dedicação amorosa, tais sujeitos se sabem unidos no fato de serem dependentes, em seu estado carencial, do respectivo outro. Além disso, visto que carências e afetos só podem de certo modo receber "confirmação" porque são diretamente satisfeitos ou correspondidos, o próprio reconhecimento deve possuir aqui o caráter de assentimento e encorajamento afetivo; nesse sentido, essa relação de reconhecimento está também ligada de maneira necessária à existência corporal dos outros concretos, os quais demonstram entre si sentimentos de estima especial.

O segundo estágio é o reconhecimento jurídico, o qual está relacionado ao reconhecimento do indivíduo como sujeito de direitos nas relações sociais, permitindo a consolidação do autorrespeito no contato com as demais pessoas do grupo social. Por conseguinte, o reconhecimento jurídico proporciona a concretização do status de cidadão, pois o indivíduo necessita tanto de proteção jurídica contra intervenções na sua esfera de liberdade, quanto segurança jurídica de que poderá participar do processo público de formação da vontade. Por esse motivo, concomitantemente às modificações do status jurídico do cidadão individual, o conjunto de atributos que caracterizam o ser humano como pessoa também foi sendo ampliado (HONNETH, 2003, p. 193).

Tanto Mead quanto Hegel entendem que no Direito exige-se a constante ampliação da liberdade, na medida em que o surgimento de um conjunto de ideais normativos aponta para a ampliação da autonomia pessoal. Há também a ampliação da própria comunidade, em decorrência da universalização dos valores particulares (MATTOS, 2006, p. 89). De acordo com Moreira (2010, p. 56), esse segundo processo é essencial para a construção da ideia de cidadania, a qual "[...] desde o início da modernidade atrela-se, necessariamente, à dignidade do indivíduo na (perante a) sociedade, a partir das garantias previstas e respeitadas pelo Estado".

Já o terceiro estágio do reconhecimento intersubjetivo é a solidariedade, que está associada ao reconhecimento, pelos parceiros da interação social, das particularidades do indivíduo. É a autocompreensão cultural que faz parte de uma sociedade que "determina os crité- 
rios pelos quais se orienta a estima social das pessoas, já que suas capacidades e realizações são julgadas intersubjetivamente, conforme a medida em que cooperam na implementação de valores culturalmente definidos" (HONNETH, 2003, p. 200). A solidariedade social está fundada na ideia de simetria das relações entre os membros da sociedade, ou seja, é a possibilidade de que qualquer pessoa tenha as suas características e especificidades reconhecidas como relevantes e necessárias (MATTOS, 2006, p. 93).

A lesão a cada uma dessas esferas causa danos à identidade do indivíduo, o que repercute também nas suas relações intersubjetivas. Honneth tinha como objetivo construir uma teoria do reconhecimento que possibilitasse refletir sobre os caminhos emancipatórios a partir do não reconhecimento.

A primeira forma de desrespeito é aquela presente nas humilhações físicas, tais como tortura e estupro, as quais retiram do indivíduo qualquer possibilidade de livre disposição do seu corpo e, consequentemente, ele é privado da sua confiança no mundo. A relação que permite que o indivíduo desenvolva a sua autoconfiança corporal é o amor (HONNETH, 2007, p. 85).

O desrespeito também pode ocorrer por meio da negação dos direitos com a consequente exclusão social, ferindo o autorrespeito. Então, ocorre a privação do status de cidadão do indivíduo, retirando dele a capacidade de pertencimento a um grupo social e, portanto, a atitude positiva que permite o reconhecimento do sujeito é o autorrespeito (HONNETH, 2007, p. 86).

Por fim, o terceiro tipo de desrespeito é a depreciação do valor social das formas de autorrealização, que tem como consequência a negação da possibilidade de os sujeitos relacionarem-se com as habilidades adquiridas ao longo de sua vida, em relação à estima social (2007, p. 87). Assim, o relacionamento positivo de reconhecimento é o desenvolvimento da autoestima, pois esta permitiria que os indivíduos encontrassem aceitação da sua individualidade.

As violações apresentadas produzem consequências nos indivíduos que são privados da sua dignidade, acarretando conflitos, tensões sociais e humilhações que podem originar uma luta por reconhecimento. Essa tensão afetiva só pode ser resolvida pelo indivíduo por meio de uma ação ativa, mas para que esta assuma a forma de uma resistência política é preciso discernimento moral, que está presente nos sentimentos negativos, como conteúdo cognitivo (HONNETH, 2003, p. 224).

A participação em movimentos coletivos de luta social desempenha um importante papel para os indivíduos envolvidos, pois tem como objetivo retirá-los de uma situação de humilhação e ainda propicia o desenvolvimento de estima mútua por meio da relação de reconhecimento e solidariedade dentro do grupo (HONNETH, 2003, p. 260). A teoria proposta por Honneth parece contribuir para a compreensão dessa situação vivenciada pelas trabalhadoras domésticas não remuneradas, visto que a atividade desenvolvida por elas não possui o mesmo valor social daquelas desempenhadas pelas mulheres que trabalham fora.

Por causa do desemprego, que não está mais meramente ligado aos ciclos econômicos, mas é agora também estrutural, um número crescente de pessoas não tem a oportunidade de ganhar o tipo de reconhecimento por suas habilidades adquiridas que eu refiro como estima social. Por causa disso, eles mal podem se considerar membros contribuin- 
tes de uma comunidade democrática organizada, já que isso pressupõe a experiência de cooperação, ou seja, a contribuição socialmente reconhecida para a reprodução social. Por esta razão, podemos esperar um número crescente de lutas por reconhecimento, direcionadas às definições institucionalizadas e medidas de estima social que governam quais atividades e habilidades podem alcançar reconhecimento simbólico ou material. Sem uma ampliação radical do significado de "trabalho", e o que pode sensivelmente e justificavelmente ser incluído dentro disso, essa luta por reconhecimento que está se aproximando não pode ser resolvida prontamente (HONNETH, 2007, p. 93).

De acordo com Honneth (2003, p. 266), apenas por meio da aquisição cumulativa de autoconfiança, autorrespeito e autoestima é que a pessoa será capaz de construir a sua identidade, enquanto um ser autônomo e de se identificar com seus objetivos e interesses.

Realizado este estudo sobre a teoria do reconhecimento desenvolvida por Axel Honneth, faz-se necessário explorar também a matriz teórica de Nancy Fraser, de modo a estabelecer relações entre ambas.

Segundo a autora, a luta por reconhecimento tornou-se a forma de conflito político no fim do século 20, na era denominada de pós-socialista. Demandas por reconhecimento das diferenças alimentam a luta de movimentos sociais mobilizados, em decorrência de questões referentes à nacionalidade, etnicidade, "raça", gênero e sexualidade (FRASER, 2001, p, 245).

Há uma modificação da sociedade relacionada à substituição gradual das lutas por redistribuição, pautadas no enfoque econômico, pelas lutas por reconhecimento, marcadas pelos conflitos de status social, devido à dominação cultural. Essa mudança, contudo, ocorre justamente no período em que a desigualdade econômica é agravada pelo desenvolvimento do capitalismo globalizante, liderado pelos Estados Unidos (FRASER, 2002, p. 62).

Diferentemente de Honneth, para quem reconhecimento está relacionado à autorrealização dos indivíduos nas relações intersubjetivas, para Fraser ele é uma questão de status social, isto é, os padrões culturais geram consequências sobre as imposições sociais que os sujeitos irão ocupar. Logo, há igualdade de status se esses padrões permitirem que os indivíduos participem da esfera social como pares (FRASER, 2003, p. 30).

Fraser (2007, p. 107-108) denomina essa perspectiva de "modelo de status" e, para a autora, o que exige reconhecimento não é a identidade específica de um grupo, mas a condição dos membros do grupo como parceiros integrais na interação social. O não reconhecimento significa não poder participar como um igual na vida social e, consequentemente, a reparação dessa injustiça requer uma política de reconhecimento, que não é sinônimo de uma política de identidade. No modelo de status a política de reconhecimento refere-se à superação do estado de subordinação para que o indivíduo possa participar com os demais membros da sociedade como igual.

Desse modo, Nancy Fraser (2001, p. 246) propõe uma teoria crítica do reconhecimento que identifique e defenda apenas versões da política cultural da diferença que possa ser corretamente combinada com a política social de igualdade. Isso porque a justiça, atualmente, requer tanto reconhecimento como redistribuição, visto que injustiças culturais acontecem em um mundo de grande desigualdade material. 
A concepção de justiça apresentada pela autora é pautada no princípio da paridade participativa, o qual requer acordos sociais que permitam a interação de todos os membros da sociedade, na condição de pares. Para tanto, duas condições devem estar presentes. A primeira é uma condição objetiva, segundo a qual a distribuição de recursos materiais deve ser feita de forma a assegurar independência e voz aos participantes. Essa condição evita formas e níveis de dependência econômica e desigualdades que impedem a paridade participativa. $A$ segunda é a condição intersubjetiva, que necessita de modelos institucionalizados de valores culturais que expressem o mesmo respeito a todos os participantes e assegurem iguais oportunidades de alcançar a estima social (FRASER, 2002, p. 67).

Em razão disso, Fraser (2003, p. 34-35) sugere uma concepção bidimensional de justiça que englobe reconhecimento e redistribuição. Segundo a autora, Honneth assume uma visão redutiva e culturalista da distribuição, pois ele pressupõe que as desigualdades econômicas estão enraizadas na ordem cultural, que privilegia certos tipos de trabalhos sobre outros. Com isso, bastaria mudar a ordem cultural para eliminar a má distribuição. Para Fraser, entretanto, nem toda má distribuição está centrada na falta de reconhecimento.

Salienta-se que no mundo real cultura e economia política estão sempre relacionadas e, assim, toda luta contra injustiça implica demandas por redistribuição e reconhecimento. A autora afirma, contudo, que as distinções analíticas são indispensáveis para compreender os dilemas políticos do nosso tempo.

Existem pessoas ou grupos de pessoas que sofrem injustiças de natureza cultural e econômica, necessitando de políticas de reconhecimento e redistribuição, de modo que apenas uma delas, de forma isolada, não será suficiente para solucionar o problema. Essas coletividades são chamadas de "ambivalentes" e gênero é um exemplo paradigmático.

A autora, portanto, defende também uma conceituação ampla e espaçosa de gênero, a fim de acomodar pelo menos dois tipos de interesses. Na perspectiva distributiva, gênero é visto como uma diferenciação presente na própria estrutura econômica da sociedade, enquanto que na perspectiva do reconhecimento gênero é uma diferenciação de status (FRASER, 2002, p. 64). Assim, não é a identidade feminina que requer reconhecimento, mas sim a condição das mulheres como parceiras plenas na interação social.

Tendo em vista todo o exposto, percebe-se que a questão da invisibilidade das mulheres que realizam trabalho doméstico requer ações políticas de redistribuição e reconhecimento. Ainda mostra-se presente na sociedade uma divisão hierárquica do trabalho pautada na separação entre trabalho reprodutivo e doméstico - responsabilidade primária das mulheres - e trabalho produtivo e pago - responsabilidade primária dos homens. Gênero também estrutura uma divisão dentro do próprio trabalho produtivo entre melhores salários - área predominantemente masculina - e os menores salários - área predominantemente feminina. Ainda que as mulheres consigam alcançar altas posições, financeiramente elas recebem menos do que os homens que ocupam o mesmo cargo. Além disso, gênero também embasa uma diferenciação cultural-valorativa, visto que há uma depreciação das mulheres que são donas de casa, seja de forma exclusiva, seja as que realizam dupla jornada, apenas valorizando-se o trabalho fora de casa. 
Diante disso, nota-se que a opressão referente ao gênero requer remédios que promovam a diferenciação (reconhecimento) e, simultaneamente, imponham medidas voltadas à promoção da igualdade social (redistribuição). A fim de compatibilizar reconhecimento e redistribuição, mitigando as interferências mútuas entre eles, Fraser (2003, p. 73-74) propõe duas estratégias que podem ser utilizadas no combate às injustiças sociais, quais sejam: medidas afirmativas e medidas transformativas.

As estratégias afirmativas têm como objetivo corrigir os resultados desiguais de arranjos sociais sem perturbar as estruturas sociais subjacentes que os geraram. Por sua vez, as estratégias transformativas, visam a corrigir resultados injustos pela reestruturação do arcabouço subjacente que os constituíram (FRASER, 2003, p. 74).

Aplicando essa diferenciação para corrigir injustiças econômicas, tem-se que os remédios afirmativos buscam realocações superficiais de bens existentes, apoia diferenciação entre grupos e pode gerar o não reconhecimento, pois, em longo prazo, acaba marcando as classes menos privilegiadas como inerentemente deficientes e insaciáveis. Já os remédios transformativos visam à reestruturação profunda das relações de produção, eliminam as diferenciações entre grupos e podem ajudar a curar algumas formas de não reconhecimento (FRASER, 2001, p. 268-273).

Essa distinção também é válida para corrigir injustiças culturais. Os remédios afirmativos estão ligados às realocações superficiais de respeito às identidades de grupos e apoiam diferenciação entre eles. Os remédios transformativos, em contraste, reestruturam profundamente as relações de reconhecimento e desestabilizam diferenciações entre grupos para permitir reagrupamentos futuros (2001, p. 270-273).

No caso das comunidades ambivalentes, Fraser (2001, p. 278-279) conclui que a meIhor solução é unir a redistribuição transformativa ao reconhecimento transformativo, pois os remédios afirmativos não alteram a estrutura que gera a injustiça econômica e social e, em longo prazo, ainda pode ter como consequência o não reconhecimento. A principal desvantagem do remédio transformativo é que as políticas culturais e econômicas não satisfazem os interesses imediatos da maior parte das pessoas.

Em razão dessas dificuldades, Fraser (2003, p. 78-79) apresenta um caminho intermediário chamado de reformas não reformistas, que são políticas com uma dupla-face. Isso porque as reformas que aparentam ser afirmativas podem ter efeitos transformativos, dependendo do contexto em que estão inseridas. De um lado, elas entrelaçam as identidades das pessoas e satisfazem algumas de suas necessidades, e, de outro, iniciam uma trajetória de mudança que pode levar a reformas mais radicais no decorrer do tempo.

Feitas as devidas considerações a respeito da teoria do reconhecimento desenvolvida por Axel Honneth e Nancy Fraser, faz-se necessário analisar a possibilidade de compatibilização dessas duas bases teóricas e a sua aplicação no reconhecimento das mulheres que realizam trabalho doméstico não remunerado. 


\section{A METÁFORA DA ROSA E A IMPORTÂNCIA DOS MOVIMENTOS FEMINISTAS}

Conforme exposto anteriormente, o núcleo da divergência entre Axel Honneth e Nancy Fraser está presente no conceito de reconhecimento e na separação deste da noção de redistribuição. Isso porque para Honneth toda luta social é uma luta por reconhecimento, enquanto Fraser distingue reconhecimento, que estaria associado ao cultural, de redistribuição, relativa ao econômico.

Celi Regina Pinto (2008, p. 36), contudo, afirma haver uma falsa antítese entre as teorias desenvolvidas por Honneth e Fraser e a melhor solução seria conservar os pontos positivos de cada uma, com o objetivo de formar uma teoria normativa da justiça voltada, principalmente, para o Brasil.

A autora explica que a distinção entre distribuição e reconhecimento realizada por Fraser precisa ser apropriada a partir de duas perspectivas. A primeira é pensar a "má-distribuição" pela posição dos agentes nas relações de produção, o que independe inteiramente do reconhecimento, não importando o estatuto que ele tenha. Essa é uma característica estrutural do capitalismo. A segunda perspectiva é a forma de apropriação pelos agentes dessa situação de injustiça. Ainda que a injustiça não exista apenas por força do autorreconhecimento dos agentes como sujeitos injustiçados, a bandeira de luta para a superação somente surge pela existência de sujeitos subjetificados como injustiçados. O que Pinto $(2008$, p. 38) propõe não é uma redução da questão social a um culturalismo radical, da qual Fraser acusa Honneth, mas sim de dois momentos distintos da questão.

Nota-se que é na segunda perspectiva que há uma limitação da teoria de Fraser, visto que apenas por meio do reconhecimento pessoal dos indivíduos da sua condição é que será possível articular um movimento social para a defesa dos seus direitos, pois "só existe dominado contra a dominação se este se reconhecer como tal. Não há feminismo antes da feminista, assim como não há paridade participativa antes do sujeito autorreconhecido como igual" (PINTO, 2008, p. 36). Por sua vez, é essa mobilização dos sujeitos que se autorreconhecem, que irá proporcionar a construção de uma conjuntura que possibilite a participação paritária.

Segundo Pinto (2008, p. 57), esse procedimento é essencial, pois permite que a distribuição não seja reduzida ao reconhecimento e, ao mesmo tempo, não limita o reconhecimento ao autorreconhecimento (autoestima) ou à política de status. Isso possibilita a compreensão da complexidade dos cenários em embate, tanto no interior na sociedade quanto nas políticas públicas.

Assim, o autorreconhecimento presente na teoria de Honneth e o modelo de status desenvolvido por Fraser não são excludentes, eles representam dois momentos distintos da elaboração teórica e da luta política, podendo complementarem-se em determinadas circunstâncias (PINTO, 2008, p. 36). Importante esclarecer que essa análise é essencial para construir o reconhecimento das mulheres que realizam trabalho doméstico em jornada integral ou não.

As mulheres trabalham mais do que os homens, sejam elas orientais ou ocidentais; sejam elas donas de casa ou trabalhadoras remuneradas. Segundo Ann Oakley lapud WOLF, 1992, p. 29), "o status moderno das tarefas domésticas é o de não serem trabalho", convenção essa que também estava presente durante os Anos Dourados. Apesar dessa naturalização do trabalho doméstico como sendo destinado às mulheres, um estudo revelou que se ele 
fosse remunerado, a renda familiar subiria em $60 \%$. De acordo com dados trazidos por Naomi Wolf (1992, p. 29), o trabalho doméstico consome 40 bilhões de horas da mão de obra francesa e, nos Estados Unidos, o trabalho voluntário das mulheres atinge 18 bilhões de dólares por ano. Muito provavelmente, se essas estatísticas fossem atualizadas os valores seriam ainda maiores.

Já as mulheres que possuem trabalho remunerado em horário integral continuam tendo de realizar também todas ou quase todas as tarefas domésticas, não havendo nenhuma alteração. Os companheiros de mulheres que realizam trabalho assalariado ajudam menos (realizam as tarefas domésticas por 36 minutos) do que os companheiros de donas de casa (ajudam nos afazeres domésticos por 1 hora e 15 minutos), observando-se que as mulheres trabalham 21 horas a mais do que os homens por semana (WOLF, 1992, p. 30).

Observa-se que não só as mulheres estão acostumadas a trabalhar mais do que os homens, como elas não recebem salário por isso. Mesmo sobrecarregadas com a dupla jornada, as mulheres conseguiram abrir fissuras na estrutura de poder, o que provocou uma violenta reação, a qual também teve como causa a constatação de que se as mulheres decidissem cobrar o pagamento atrasado pela dupla jornada, os custos aos empregadores e ao governo seriam extremamente altos (WOLF, 1992, p. 31).

Segundo Nancy Fraser (2009, p. 16), o neoliberalismo foi responsável por ressignificar a crítica feminista ao androcentrismo, "[...] cultura política do capitalismo organizado pelo Estado [...]" que "[...] visualizava o cidadão de tipo ideal como um trabalhador masculino pertencente à maioria étnica - chefe e homem de família". Ademais, tem-se a construção do "salário família", pelo qual o salário recebido pela mulher era considerado apenas suplementar, o ideal seria que o homem o recebesse de forma exclusiva.

Nesse ínterim, as feministas da segunda onda rejeitaram a associação exclusiva de injustiça com má distribuição e se uniram a outros movimentos emancipatórios. Elas ampliaram o significado de justiça, analisando as desigualdades sociais presentes na família, na sociedade civil e na vida cotidiana. Elas focaram não apenas em questões relacionadas a gênero, mas também à classe, à raça, à sexualidade e à nacionalidade (FRASER, 2009, p. 18).

Elas criticaram o salário familiar, enquanto núcleo da má distribuição de gênero, da falta de reconhecimento e de representação. O objetivo, entretanto, não era valorizar exclusivamente o trabalho remunerado. As feministas buscavam transformar as estruturas do sistema, contestando o androcentrismo que privilegiava o lucro em detrimento das pessoas (GUTTING; FRASER, 2015).

Com o neoliberalismo, há uma ampliação do movimento feminista, ao mesmo tempo em que há uma modificação dos seus ideais. Com a entrada das mulheres nos mercados de trabalho em todo o mundo, o efeito foi eliminar o ideal do salário familiar do capitalismo organizado pelo Estado. No capitalismo neoliberal "desorganizado", este ideal foi substituído pelo da família de dois assalariados, pouco importando que a realidade implícita nesse novo ideal seja caracterizada por níveis salariais reduzidos, diminuição da segurança no emprego, padrões de vida em declínio, aumento no número de horas trabalhadas, exacerbação do turno dobrado - agora, normalmente, turno triplo ou quádruplo - e um aumento de lares chefiados por mulheres (FRASER, 2009, p. 25). 
Em razão disso, a emancipação da mulher passou a estar condicionada ao acúmulo capitalista e a crítica ao androcentrismo serve, hoje, para valorizar o trabalho assalariado. Desse modo, o feminismo tornou-se incapaz de promover a igualdade entre as próprias mulheres (GUTTING; FRASER, 2015).

Para mim, o feminismo não deve se preocupar em fazer um número limitado de mulheres assumir posições de poder e privilégio dentro de hierarquias sociais existentes, e sim de superá-las. Para isso, é necessário desafiar as fontes estruturais da dominação de gênero na sociedade capitalista - acima de tudo, a divisão institucionalizada de dois tipos de atividades supostamente distintos: de um lado, o chamado trabalho de "produção", historicamente assalariado e associado aos homens; de outro, as tarefas ligadas ao "cuidado", historicamente não remuneradas e ainda realizadas sobretudo por mulheres. Na minha opinião, essa divisão sexual hierarquizada entre "produção" e "reprodução" é uma estrutura determinante da sociedade capitalista e grande causa das assimetrias de gênero inerentes a ela. As mulheres não poderão se emancipar enquanto essa estrutura permanecer intacta (GUTTING; FRASER, 2015).

Nota-se uma perpetuação da ausência de identidade das mulheres que realizam tarefas domésticas, em moldes semelhantes aos dos anos 60, época em que foi publicado o livro Laços de Família. A dona de casa não é considerada um sujeito autônomo, pertencente a si mesma, ela pertence à sua família. Diante disso, o reconhecimento social passou a ser alcançado por meio do trabalho, do ingresso da mulher no universo concorrencial e meritocrático, tradicionalmente destinado aos homens (LIPOVETSKY, 1997, p. 205-219).

Ante o exposto, faz-se necessário, primeiramente, que as mulheres que realizam trabalho doméstico enfrentem a "[...] questão da identidade e, principalmente, da constituição do sujeito de luta. E neste momento o reconhecimento não é apenas uma questão de justiça social, mas de autorreconhecimento, de autoestima e de luta pelo reconhecimento do outro" (PINTO, 2008 , p. 45). Esse processo é caracterizado no conto "A imitação da rosa" por meio do momento epifânico vivido por Laura quando ela observa as rosas, as quais fazem com que ela relembre o seu passado, buscando romper com a ausência de identidade e de reconhecimento.

A partir disso abre-se a possibilidade para que as feministas militem no sentido de valorizar as atividades não remuneradas, descentralizando a identidade construída apenas com base no trabalho assalariado das mulheres. O que se defende não é a submissão da mulher ao marido, como chefe de família, mas sim o seu reconhecimento como sujeito de direitos que possui um trabalho que precisa ser respeitado.

Por conseguinte, essas mulheres que foram excluídas socialmente passam a se constituírem como promotoras da ação social por meio da sua construção como agentes e a participarem na condição de pares na esfera social. A paridade participatória deve ocorrer entre homens e mulheres e entre as mulheres que realizam trabalho assalariado e trabalho não remunerado.

\section{CONSIDERAÇÕES FINAIS}

A função pedagógica da arte é revelada no momento em que é possível verificar que os temas abordados pela literatura permanecem atuais e despertam o interesse dos indivíduos, alargando a sua interpretação. 
Na presente pesquisa buscou-se discutir como o movimento feminista conseguirá assegurar os direitos e o respeito das mulheres que realizam trabalho doméstico não remunerado e das que possuem dupla jornada, em decorrência da sua falta de reconhecimento, uma vez que ele sequer é visto como um trabalho pela sociedade e é quase que, exclusivamente, desempenhado por mulheres.

A ausência de reconhecimento foi abordada com base no conto "A imitação da rosa", de Clarice Lispector, o qual foi publicado no livro Laços de Família em 1960, época em que as muIheres eram aconselhadas a assumirem performances apropriadas ao desempenho dos seus papéis femininos, a fim de manter as relações de gênero. Inserida nesse contexto, Laura, protagonista do conto, sofre um conflito interno, pois não mais quer se submeter às convenções exigidas pela sociedade. Ela não se reconhece e não é reconhecida como possuidora de uma identidade e como sujeito de direitos.

Muito embora vários anos tenham se passado desde a publicação desse conto e vários direitos tenham sido conquistados pelo movimento feminista, inclusive o direito ao trabalho da mulher, atualmente as tarefas domésticas permanecem não sendo respeitadas como exercício de um trabalho e não são objeto de luta pelas feministas.

Segundo Nancy Fraser, a segunda onda do movimento feminista subordinou a sua crítica radical ao neoliberalismo, uma vez que a crítica ao salário familiar foi substituída pela valorização da família de dois assalariados, não importando em que condições o trabalho é exercido. Dessa forma, o feminismo, atualmente, não é capaz nem de garantir a igualdade entre as mulheres.

Por esse motivo, é importante a conjugação da teoria do reconhecimento desenvolvida por Axel Honneth com a da Nancy Fraser, a fim de tornar possível uma política identitária, ampliando as discussões referentes à visibilidade das mulheres que são donas de casa. É fundamental, portanto, que o reconhecimento parta das próprias mulheres, pois na medida em que os grupos despossuídos de direitos se autoconstituírem como carentes pela presença de um outro, por sua vez, constituído por muitos direitos, isso possibilitará alcançar uma igualdade participatória defendida por Fraser.

O neoliberalismo foi responsável por incluir novas temáticas no movimento feminista, permitindo uma interseção entre gênero, raça, sexualidade e nacionalidade, ao mesmo tempo em que alterou os seus ideais, valorizando apenas o trabalho remunerado. Ele delineou, sob o pretexto de crítica ao androcentrismo, uma armadilha para as mulheres. Elas têm de trabalhar mais horas, recebendo baixos salários e ainda possuem dupla jornada em casa, realizando tarefas (trabalhos) domésticas que não são reconhecidas pelas próprias mulheres, e tampouco pela sociedade.

Desse modo, o feminismo deve, na verdade, superar as estruturas de gênero presentes na sociedade, em especial a divisão entre trabalho produtivo assalariado, tradicionalmente destinado ao homem, e as tarefas ligadas ao "cuidado", historicamente não remuneradas e associadas à mulher, ao invés de consolidar essa estrutura ao se preocupar apenas com o acesso das mulheres aos altos cargos corporativos. Somente assim será possível a emancipação das mulheres que realizam trabalho doméstico não remunerado. 


\section{REFERÊNCIAS}

BARBOSA, M. J. S. Clarice Lispector: desfiando as teias da paixão. Porto Alegre: EDIPCRS, 2001.

CANDIDO, A. Vários escritos. 5. ed. Rio de Janeiro: Ouro sobre azul, 2011.

COQUEIRO, W. S.; SEGATO, M. C. A identidade existencial feminina no conto "A imitação da rosa" de Clarice Lispector. Revista Intertexto, Uberaba, v. 5, n. 1, p.1-14, jan./jun. 2012.

DEL PRIORE, M. Histórias e conversas de mulher. São Paulo: Planeta, 2013.

FRASER, N. Da redistribuição ao reconhecimento? Dilemas da justiça na era pós-socialista. In: SOUZA, J. (org.). Democracia hoje: novos desafios para a teoria democrática contemporânea. Brasília: Editora UnB, 2001. p. 245282.

FRASER, N. O feminismo, o capitalismo e a astúcia da história. Mediações - Revista de Ciências Sociais [on-line], Londrina, v. 14, n. 2, p. 11-33, jul./dez. 2009. Disponível em: http://www.uel.br/revistas/uel/index.php/mediacoes/article/view/4505/3782. Acesso em: 20 jul. 2016.

FRASER, N. Políticas feministas na era do reconhecimento: uma abordagem bidimensional da justiça de gênero. In: BRUSCINI, C.; UNBEHAUM, S. G. (org.). Gênero, democracia e sociedade brasileira. São Paulo: FCC; Editora 34, 2002. p. 61-78.

FRASER, N. Reconhecimento sem ética? Lua Nova [on-line], São Paulo, n. 70, p. 101-138, 2007. Disponível em: http://www.scielo.br/scielo.php?script=sci_arttext\&pid=S0102-64452007000100006\&lng=en\&nrm=iso. Acesso em: 18 jul. 2016.

FRASER, N. Social justice in the age of indentify politics: redistribution, recognition, and participation. In: FRASER, N.; HONNETH, A. Redistribution or recognition? A political-philosophical Exchange. Londres; Nova York: Verso, 2003. p. 7-109.

GUTTING, G.; FRASER, N. A feminism where "lean in" means leaning on others. The New York Times [on-line], Nova York, 15 out. 2015. Disponível em: http://opinionator.blogs.nytimes.com/2015/10/15/a-feminism-whereleaning-in-means-leaning-on-others/?_r=2. Acesso em: 20 jul. 2016.

HELENA, L. Nem musa, nem medusa: itinerários da escrita em Clarice Lispector. Niterói: EDUFF, 1997.

HONNETH, A. Lutas por reconhecimento: a gramática moral dos conflitos sociais. São Paulo: Editora 34, 2003.

HONNETH, A. Reconhecimento ou redistribuição? A mudança de perspectivas na ordem moral da sociedade. In: SOUZA, J.; MATTOS, P. (org.). Teoria crítica no século XXI. Pinheiros: Annablume, 2007. p. 79-93.

LIPOVETSKY, G. A terceira mulher: permanência e revolução do feminino. Lisboa: Instituto Piaget, 1997.

LISPECTOR, C. Laços de Família. Rio de Janeiro: Rocco, 1998.

MATTOS, P. C. A sociologia política do reconhecimento: as contribuições de Charles Taylor, Axel Honneth e Nancy Fraser. São Paulo: Annablume, 2006.

MOREIRA, N. C. Fundamentos de uma teoria da constituição dirigente. Florianópolis: Conceito Editorial, 2010.

PINSKY, C. B. Mulheres dos anos dourados. São Paulo: Contexto, 2014.

PINTO, C. R. Nota sobre a controvérsia Fraser-Honneth informada pelo cenário brasileiro. Lua Nova [on-line], São Paulo, n. 74, p. 35-58, 2008. Disponível em: http://www.scielo.br/scielo.php?pid=S0102-64452008000200003\&script=sci_abstract\&tIng=pt. Acesso em: 19 jul. 2016.

WOLF, N. O mito da beleza: como as imagens de beleza são usadas contra as mulheres. Rio de Janeiro: Rocco, 1992. 